Vol.15, No. 57, October, 2020, 1092-1101

\title{
JAUES
}

\section{BEHAVIOR OF REINFORCED CONCRETE COLUMNS CONFINED WITH PRESTRAINED SHAPE MEMORY ALLOY PLATES}

\author{
Amr M. Hilal \\ Structural Engineering Department, Faculty of Engineering, Al-Azhar University, Cairo, \\ Egypt. \\ E-mail: amrriad20@yahoo.com
}

\begin{abstract}
:
External confinement of concrete columns increases the column capacities. This is essential for deficient columns to restore their named capacity, or for safe columns to enhance their capacities if required. This paper introduces a simple technique using the superior properties of shape memory alloys (SMA) to actively confine circular concrete columns. The SMA plates were tensioned prior to confinement and placed in their exact locations. The temperature change was applied after the plates were placed on the columns, leading the SMA plates to compress the columns.

The experimental program consisted of six circular concrete columns specimens $(100 \mathrm{~mm}$ diameter, $600 \mathrm{~mm}$ height). The parameters studied in the experimental program are the applied tension force to the external stirrups prior to the confinement process, and type of confinement (active or passive). The increase of the column capacities due the active SMA confinement was observed, as well as the change of the column behavior after active confinement. Finite element models were performed using ABAQUS software to verify the experimental results. The paper concluded an increase of (17\%-38\%) in the column capacities compared with the unconfined column. The finite element analysis showed close results to the experiment program, which could lead to a future wide range study to generalize this simple technique on different concrete columns.
\end{abstract}

\section{KEYWORDS: Active Confinement, New Technique, Smart Materials, Circular Columns, External Stirrups, Prestressing, Reinforced Concrete.}

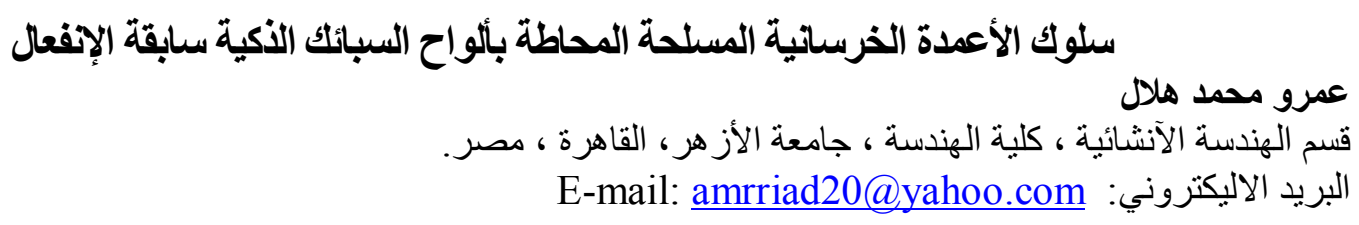

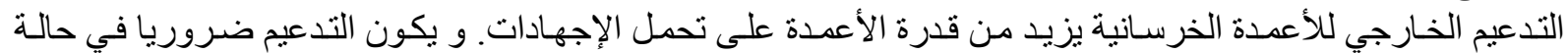

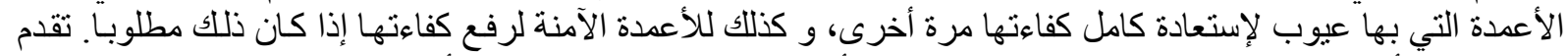

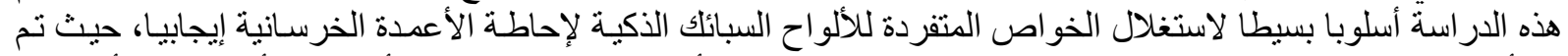

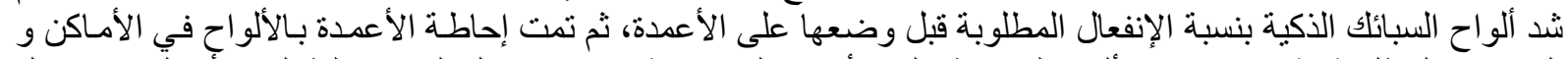

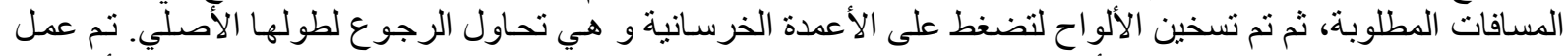

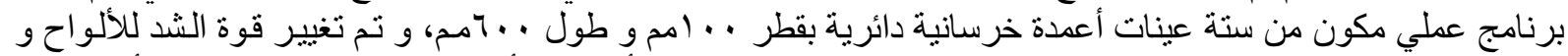

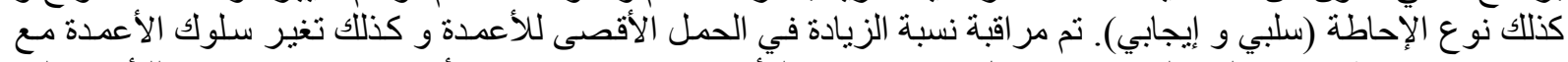

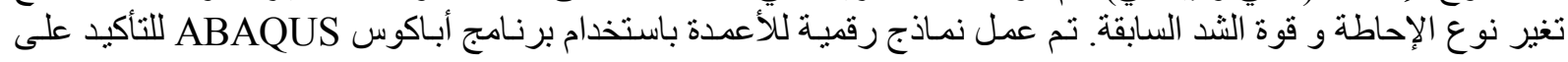




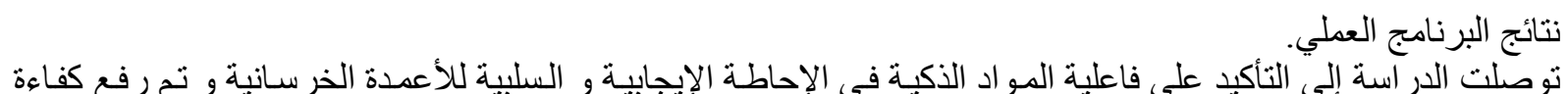

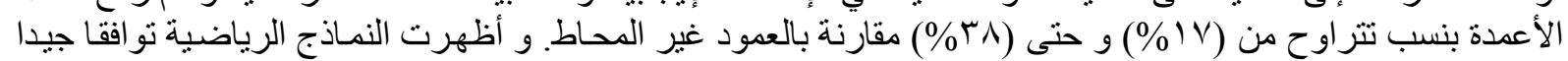

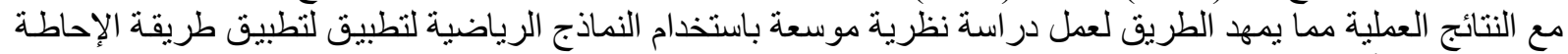
المقترحة على أعمدة خرسانية مختلفة لمهن.

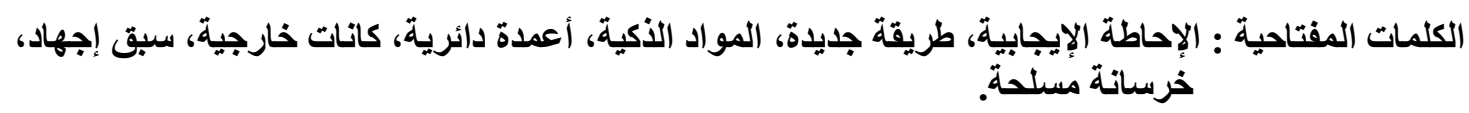

\section{INTRODUCTION}

Enhancement of column capacities could be essential if columns are proven to be deficient due to design or construction mistakes. Moreover, some loads on columns could increase due to change of building use or increase of number of floors.

Column confinement is an effective method to increase the column capacities. The confinement techniques are divided into two main types: passive and active confinement. The main difference between the two methods is the application of external pressure in the active confinement method, while passive confinement depends only of the side elongation of concrete against the external stirrups as shown in Fig. 1a. and 1b. (Shin, M.and Andrawes, B. (2010), Andrawes, B. et.al. (2010)). Although active confinement gives better results, the simplicity of the passive technique makes it preferable in the strengthening works.

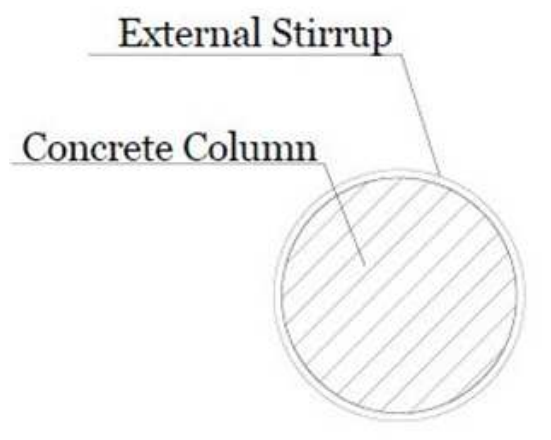

No Lateral Pressure

a) Passive Confinement using External Stirrups

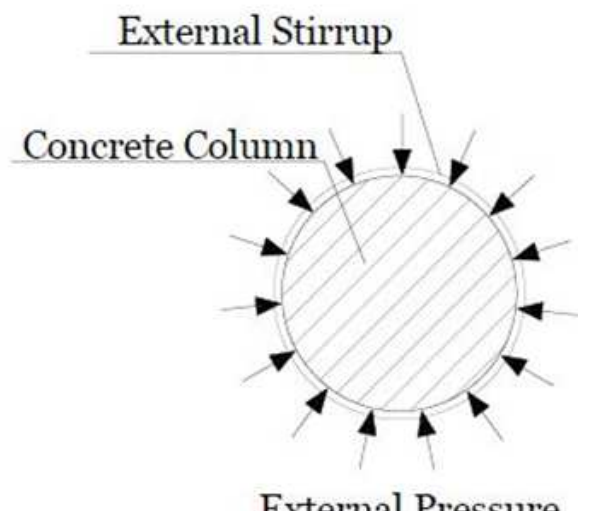

b) Active Confinement using External Stirrups

Fig. 1: Schematic External Confinement of Concrete Columns

Passive confinement has also the advantage of having settled and verified equations to predict the percentage of capacity increase. Several models have predicted this increase. These models expressed the capacity increase in the form of increased concrete compressive strength $\left(\mathrm{f}^{\prime}{ }_{\mathrm{cc}}\right)$. The new compressive strength depended mainly on the original compressive strength of concrete, the spacing, yield strength and number of external stirrups. The following relation for strength of prediction of strength increase in passive confined concrete was predicted by Mander et al. (1988) and is used in the American Code of Practice ACI 440.2R-17 (2017):

$f_{c o}^{\prime}=f_{c o}^{\prime}\left(-1.254+2.254 * \sqrt{1+\frac{7.94 * f_{l}^{\prime}}{f_{c o}^{\prime}}}-2 \frac{f_{l}^{\prime}}{f_{\sigma o}^{\prime}}\right)$

$f_{l}^{\prime}=\frac{1}{2} k_{\varepsilon} \rho_{s} f_{y h}$

$k_{\varepsilon}=\frac{\left(1-\frac{s^{\prime}}{2 d_{s}}\right)^{2}}{1-\rho_{c e}}$ 
$\rho_{s}=\frac{A_{s p} * \pi * d_{s}}{\frac{\pi}{4} * d_{s}^{2} * s}$

where;

$\mathrm{f}_{\mathrm{cc}}=$ the strength of confined concrete at failure, $\mathrm{f}_{\mathrm{co}}=$ unconfined concrete compressive strength, $\mathrm{f}_{1}=$ effective lateral confining pressure, $\mathrm{f}_{\mathrm{yh}}=$ the yield strength of transverse reinforcement, $\mathrm{k}_{\mathrm{e}}=$ the confinement effective coefficient, $\rho_{\mathrm{cc}}=$ the ratio of the area of the axial steel to the area of the core of the section, s' $=$ the clear spacing between the spiral, $\rho_{\mathrm{s}}=$ the transverse reinforcement ratio, $A_{s p}=$ area of transverse reinforcement bar, $d_{s}=$ the diameter of the spiral between bar centers, $\mathrm{s}=$ the spacing between the stirrups.

This paper introduces an active confinement technique, which is proven effective, yet easy to gain the advantages of the active method in a simple way. This is achieved through the use of external stirrups made out of shape memory alloys. Prestrained SMA-plates are put on the concrete columns and heated to return to their original shape. Through this process the required external pressure is applied on the columns and active confinement is reached .

A previous research program (Atia, E., (2019)) compared using SMA-plates in the active confinement of columns with other methods, but used a different technique by applying the pressure through bolt stressing. This ignored the special properties of SMA, which are studied here.

\section{THEORETICAL BACKGROUND}

In this section the general concept of SMA is briefly explained. The special type of SMAplates used in the experimental program is also introduced.

\subsection{Properties of SMAs}

SMAs are able to undergo large deformations (up to 8\%) and return to their original shape upon heating. These special properties are mainly due to the back and forth transformation between the martensite phases and the austenite phases on the atomic level. The austenite and martensite phases are closely related to the state of the SMA in its high temperature and low temperature. The SMA's are dependent on two transformation temperatures, austenite finish temperature (Af) and martensite finish temperature (Mf) (Abdelrahman, K. and El-Hacha, R. (2015)). Fig. 2 shows the changes of strains of the SMA related to temperature change.

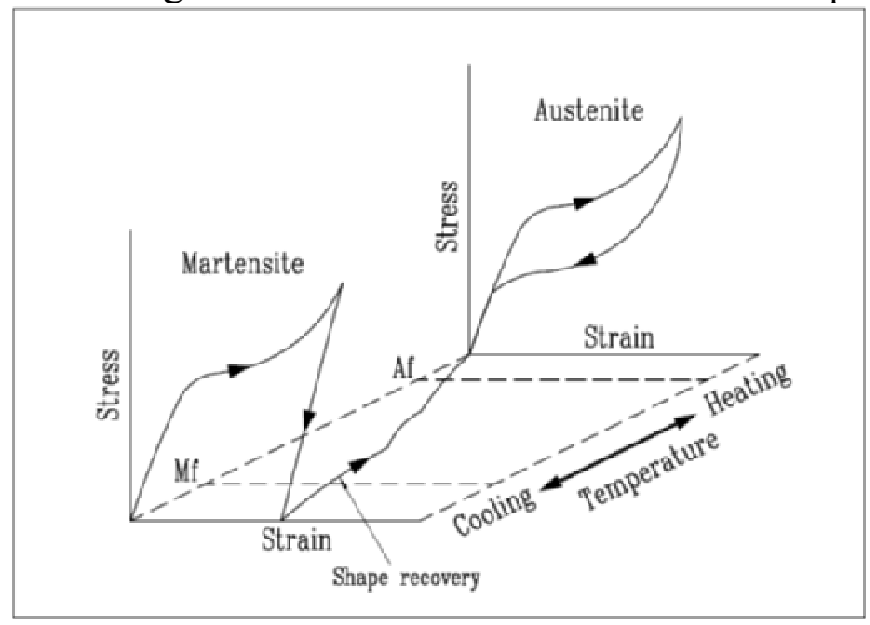

Fig. 2: Mechanical Behavior of SMA

At temperatures below Mf where the alloy is in its martensite phases, the SMA behaves plasticly. If the SMA is heated above the temperature Af, the alloy transforms to austenite and the SMA recovers its original shape (super-elasticity). That phenomenon is known as shape memory effect (SME) (Shin, M. (2012)). The SME phenomenon is associated with large stress recovery at restrain of the SMA to restore its original shape. This level of stress is closely related to the material composition, and the amount of prestrain. Due to this reversible process, SMAs maybe used in several applications and appears to be one of the main materials of the future. SMAs have already been used for multiple applications within the biomedical field (eyeglasses, dental wires, and reinforcement for arteries and veins), and aerospace industries (fixed wing and rotary-wing components) in the past. Recently, they 
have also started to attract a lot of attention in other engineering fields due to the price decrease that has occurred over the past decade. This price reduction is expected to continue within the near future and should radically continue due to the eventual increase in both iron and copper-based alloys (Park, J. et.al. (2011), Choi, E. et.al. (2013)).

\subsection{SMA plates used in the Experimental Program}

SMA have different types depending on the chemical composition of the alloy. The used alloy consisted of Nickel (Ni) and Titanium (Ti) with an atomic percentage of $55 \%$ and $44 \%$. The SMA plates could provide a linear strain recovery up to $8 \%$ when heated above a temperature of $23^{\circ} \mathrm{C}$. This temperature range was specifically chosen because it is easy to reach. The SMA plates have been supplied by the manufacturer in its martensitic pre-strained stage. According to the manufacturer, the ultimate tensile strength, elastic modulus, and strain at failure of the SMA plate were $896 \mathrm{MPa}, 84821 \mathrm{MPa}$, and $18 \%$, respectively.

\section{EXPERIMENTAL PROGRAM}

Six RC columns with overall dimensions of $100 \mathrm{~mm}$ diameter, $600 \mathrm{~mm}$ height were tested. The molds were precisely cut from a polyvinyl chloride (PVC) plastic pipe, such that their inside surface was smooth and they were all very similar in geometry. A concrete mix targeting $22.5 \mathrm{MPa}$ at 28 days was used in casting the columns. The longitudinal and transverse reinforcement of all specimen was $4 \# 10 \mathrm{~mm}$ bars longitudinally and $\# 4 \mathrm{~mm}$ diameter bars at $85 \mathrm{~mm}$ spacing in the transverse direction. Three additional \#4mm stirrups and one layer of CFRP at $100 \mathrm{~mm}$ width were applied at the beginning and end of each column to avoid local failure. The external stirrups were SMA-plates with the dimensions and shape shown in Fig. 3.

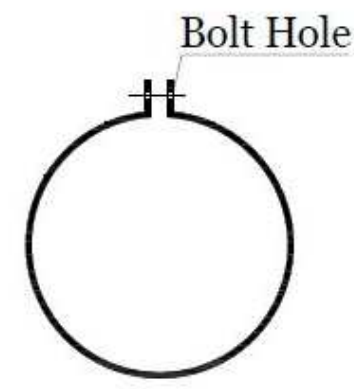

Length $=380 \mathrm{~mm}$

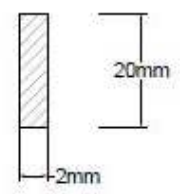

Plate Section

Fig. 3: Dimensions and Shape of SMA- Plate

The test specimens were divided into five columns and a reference column depending on the level of pretension force of the external stirrups as shown in Table 1, while the reinforcement details are shown in Fig. 4.

Column (C-1) was considered as a reference specimen, without any type of confinement. Column (C-2) was passively confined and the temperature of external stirrups was smaller than $15 \square$. Column (C-3) was passively confined and the temperature of external stirrups was bigger than $23 \square$. Columns (C-4, C-5 and C-6) were actively confined, the temperature of external stirrups was higher than $23^{\circ} \mathrm{C}$ and tension of external stirrups by 2000,4000 and 6000 $\mathrm{N}$ respectively.

The tests were performed in the RC Lab., the Faculty of Engineering, Al-Azhar University. The hydraulic jack used in testing was with capacity 100 ton. Fig. 5 shows the general setup of the test frame, the hydraulic jack and the specimen. 
Table 1: Specific Parameters for Column Specimen

\begin{tabular}{ccccc}
\hline Specimen \# & $\begin{array}{c}\text { Spacing of } \\
\text { External } \\
\text { Stirrups }(\mathrm{mm})\end{array}$ & $\begin{array}{c}\text { Temperature } \\
(\square)\end{array}$ & $\begin{array}{c}\text { Type of } \\
\text { Confinement }\end{array}$ & $\begin{array}{c}\text { Pretension } \\
\text { force } \\
(\mathrm{N})\end{array}$ \\
\hline $\mathrm{C}-1$ & & \multicolumn{2}{c}{ Reference Column } & \\
\hline $\mathrm{C}-2$ & 85 & $\leq 15$ & Passive & 0 \\
\hline $\mathrm{C}-3$ & 85 & $\geq 23$ & Passive & 0 \\
\hline C-4 & 85 & $\geq 23$ & Active & 2000 \\
\hline C-5 & 85 & $\geq 23$ & Active & 4000 \\
\hline C-6 & 85 & $\geq 23$ & Active & 6000 \\
\hline
\end{tabular}

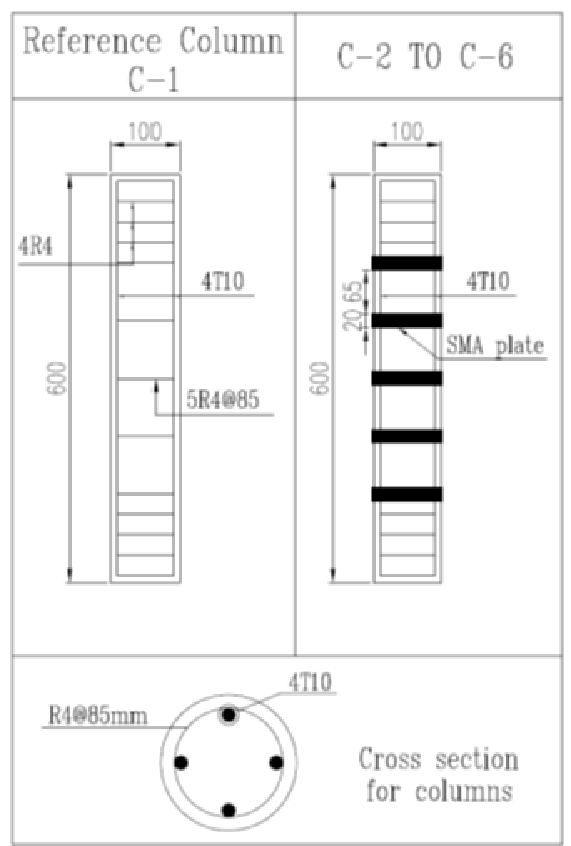

Fig. 4: Details of Reinforcement for All Columns

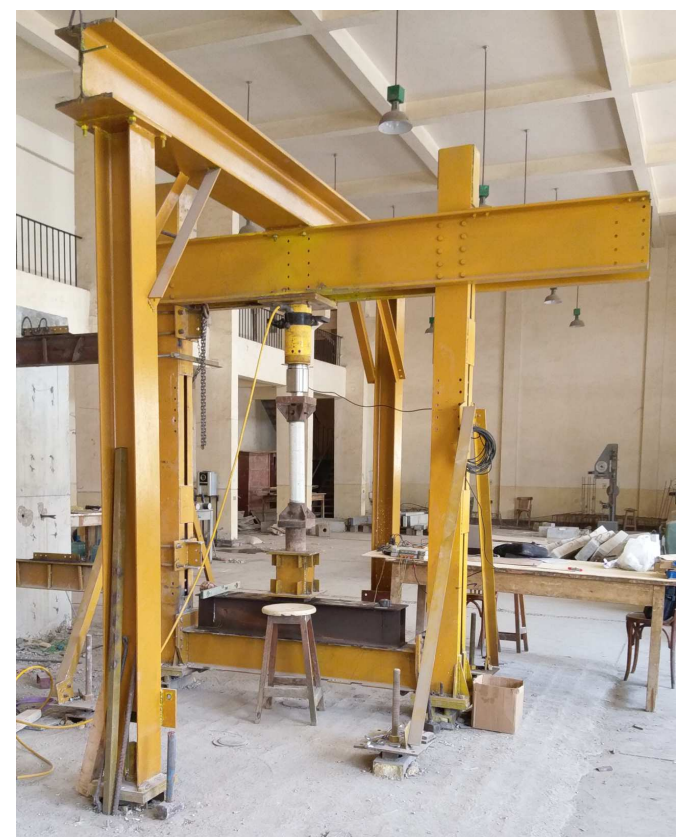

Fig. 5: General Test Setup

The SMA-plates were mounted on a fixed rig and tensioned using a torque wrench to the required stress. This procedure was controlled by gluing a strain gauge on the tensioned plate. After reaching the desired strain the plates were placed on the columns and attached by a bolt, and heated by pouring ordinary hot water to achieve the required pressure on the concrete column. The tensioning procedure is shown in Fig. 6.

\section{TEST RESULTS}

Columns were tested under static load and the results, cracks and behavior were observed and recorded precisely. Testing showed an increase in the column capacity of about $17 \%$ for the passively confined column (C-2) up to $38 \%$ for the specimen $(\mathrm{C}-6)$. The external stirrups served in arresting the failure cracks. The actively confined columns showed more ductile behavior and less cracks before failure. Fig. 7 shows crack pattern of all columns. 

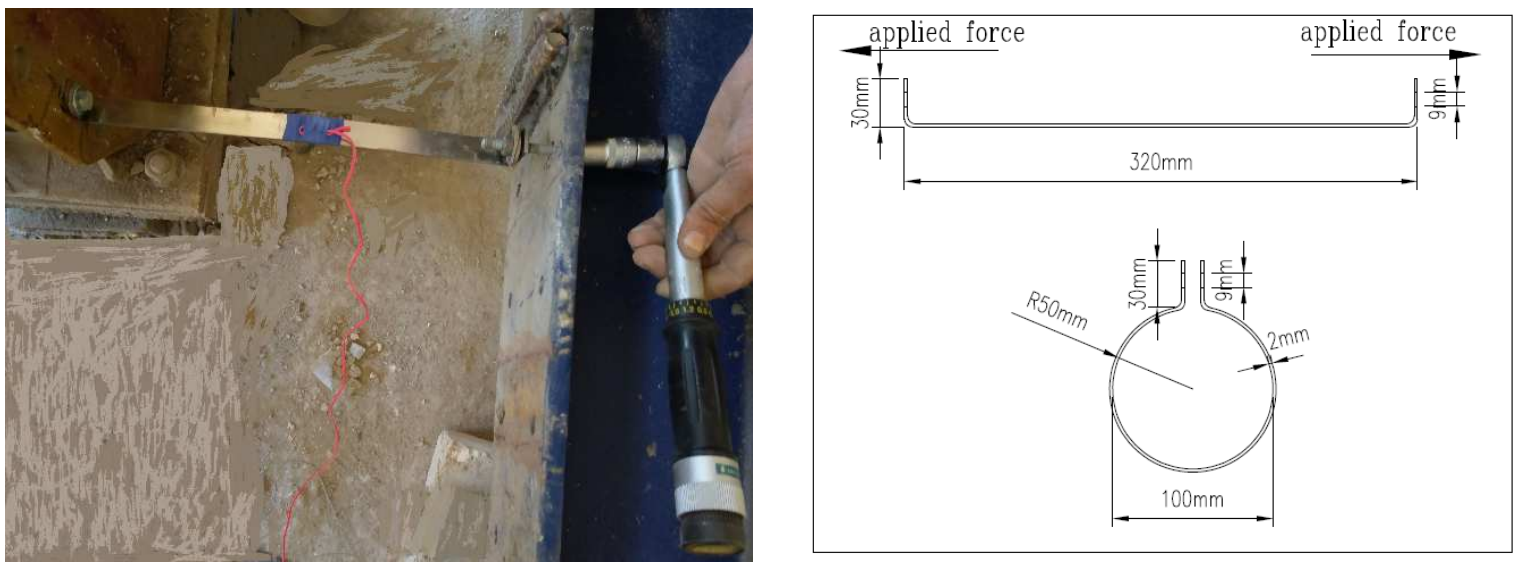

Fig. 6: Tensioning Procedure
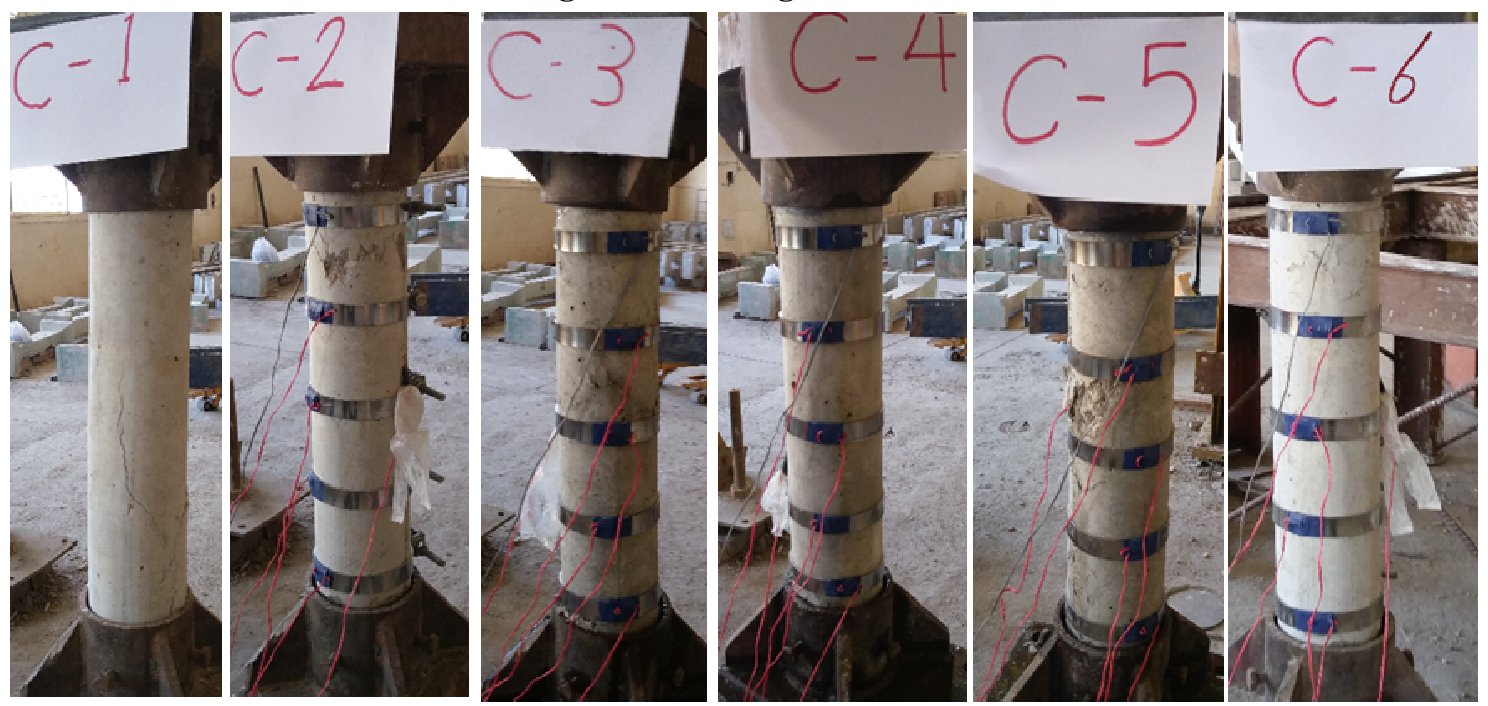

Fig. 7: Crack Pattern for All Specimen

\subsection{Steel Strains}

The longitudinal steel strains were obtained from the electrical strain gauges. Fig. 8 shows the load steel strain curves, through the load history, for the all columns at the first third span section. The actively confined columns reduced the steel strains in the longitudinal column reinforcement at the same load level. The higher the preloading level of the SMA-plates, the lower the steel strains at the same load level.

\subsection{SMA-Plates Strains}

The SMA strains at the mid height of the columns were obtained from the electrical strain gauges. Fig. 9 shows the load SMA strain curves through the load history. The pretensioned SMA-plates showed similar behavior regardless the initial prestrain of the plates, with low strains even at high load levels. While the non-preloaded SMA-plates showed quicker response and larger strains at the same load levels.

\section{ANALYTICAL MODELS}

The specimens were modeled using finite element analysis on the well-known software ABAQUS. The analysis was based on the non-linear iterative secant stiffness formulation. Concrete Damaged Plasticity model was used to describe the yield criterion of concrete as compressive behavior and tension behavior .

The reinforced concrete column was idealized using three different types of elements. Concrete was represented by an eight-node solid element (C3D8R) with 24 degrees of freedom. The reinforcement was represented by a truss element (T3D2) with 6 degrees of freedom. SMA was represented by an eight-node solid element (C3D8R) with 24 degrees of freedom. The contact between concrete and SMA was represented by tie behavior. 


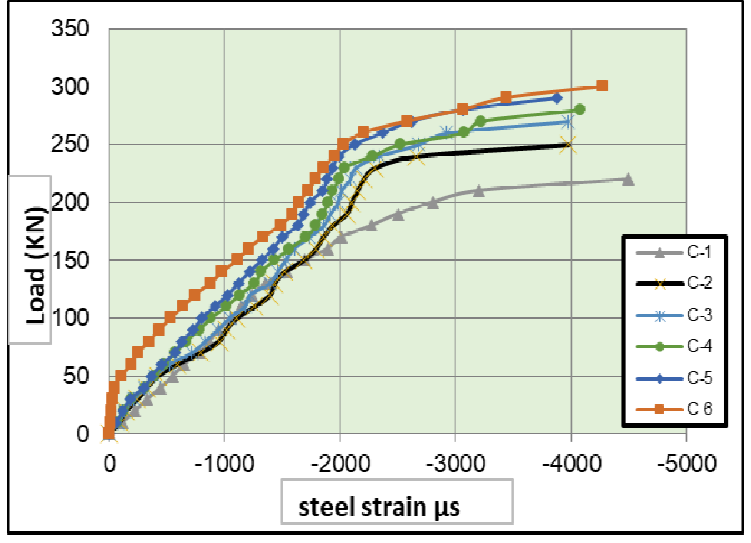

Fig. 8: Comparison between longitudinal Steel strain at first third for all columns

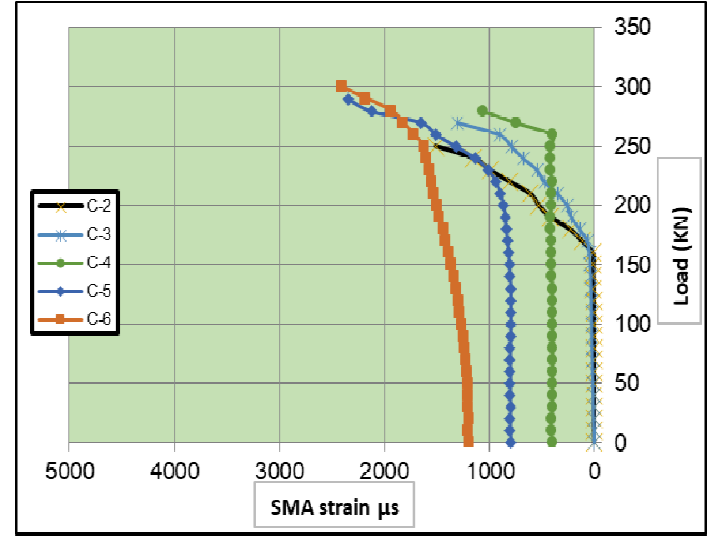

Fig. 9: Comparison between longitudinal SMA strain at midpoint for all columns

Fig. 10 shows the deformed shape of the model of the control column (C-1). The verification of the numerical model has shown good agreement with the experimental results. Comparison between experimental and analytical results is shown in Table 2.

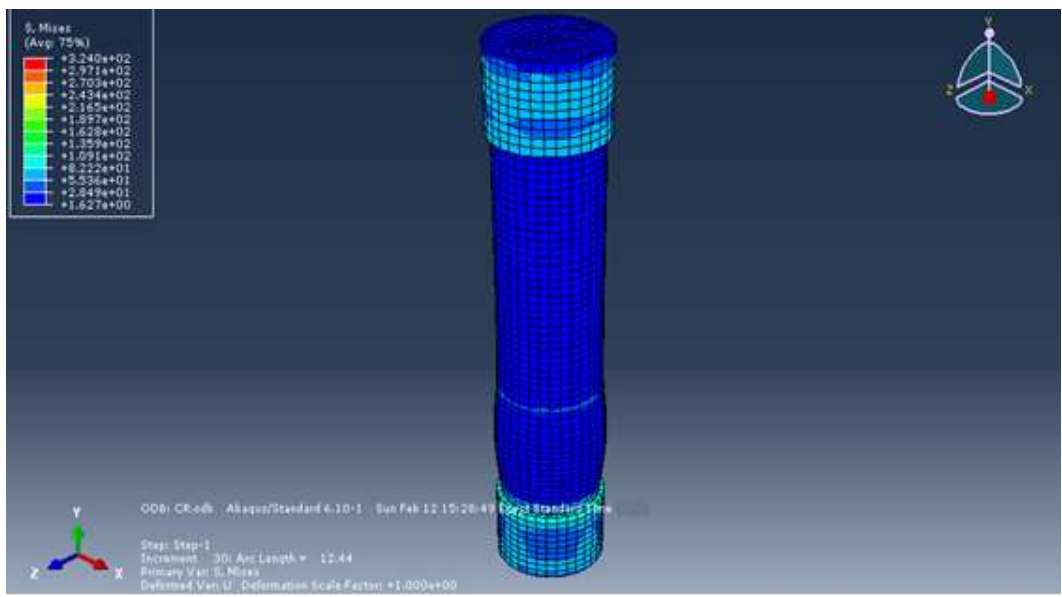

Fig. 10: Deformed Shape of Analytical Model of Specimen (C-1)

Table 2. Comparison between the Experimental and FEA Failure Loads

\begin{tabular}{cccc}
\hline Specimen $\#$ & \multicolumn{2}{c}{ Failure Load $(\mathrm{kN})$} & Precision \\
\cline { 2 - 4 } & EXP. & FEA & FEA/EXP \\
\hline C-1 & 220 & 226 & 1.03 \\
\hline C-2 & 258 & 261 & 1.01 \\
\hline C-3 & 277 & 278 & 1.00 \\
\hline C-4 & 280 & 285 & 1.02 \\
\hline C-5 & 290 & 292 & 1.00 \\
\hline C-6 & 302 & 299 & 0.99 \\
\hline
\end{tabular}

\subsection{Steel Strains}

The steel strains were obtained out of ABAQUS for the different specimens and compared with the steel strains in the experimental program. The graphs showed good agreement especially in the plastic stage of the load history. Fig. 11 shows the load- steel strain curves for each specimen, obtained from FEA and experimentally. 

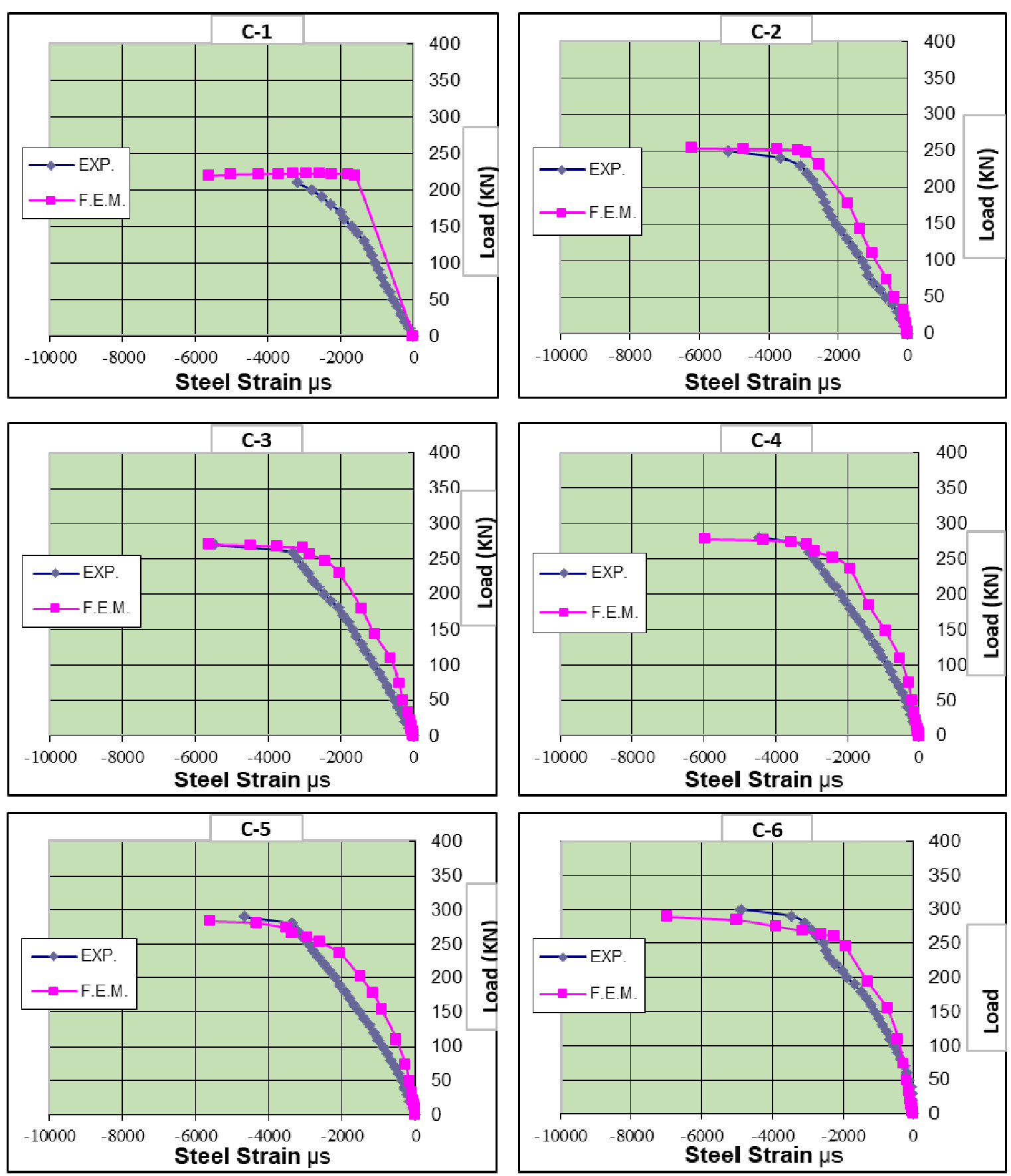

Fig. 11: Comparison between Experimental and Analytical Steel Strain for All Columns

\subsection{SMA-Plate Strains}

The SMA-plate strains were obtained out of ABAQUS for the different specimens and compared with the SMA-plate strains in the experimental program. The graphs also show very good agreement all through the load history of the specimens. Fig. 12 shows the loadSMA strain curves for each specimen, obtained from FEA and experimentally. 

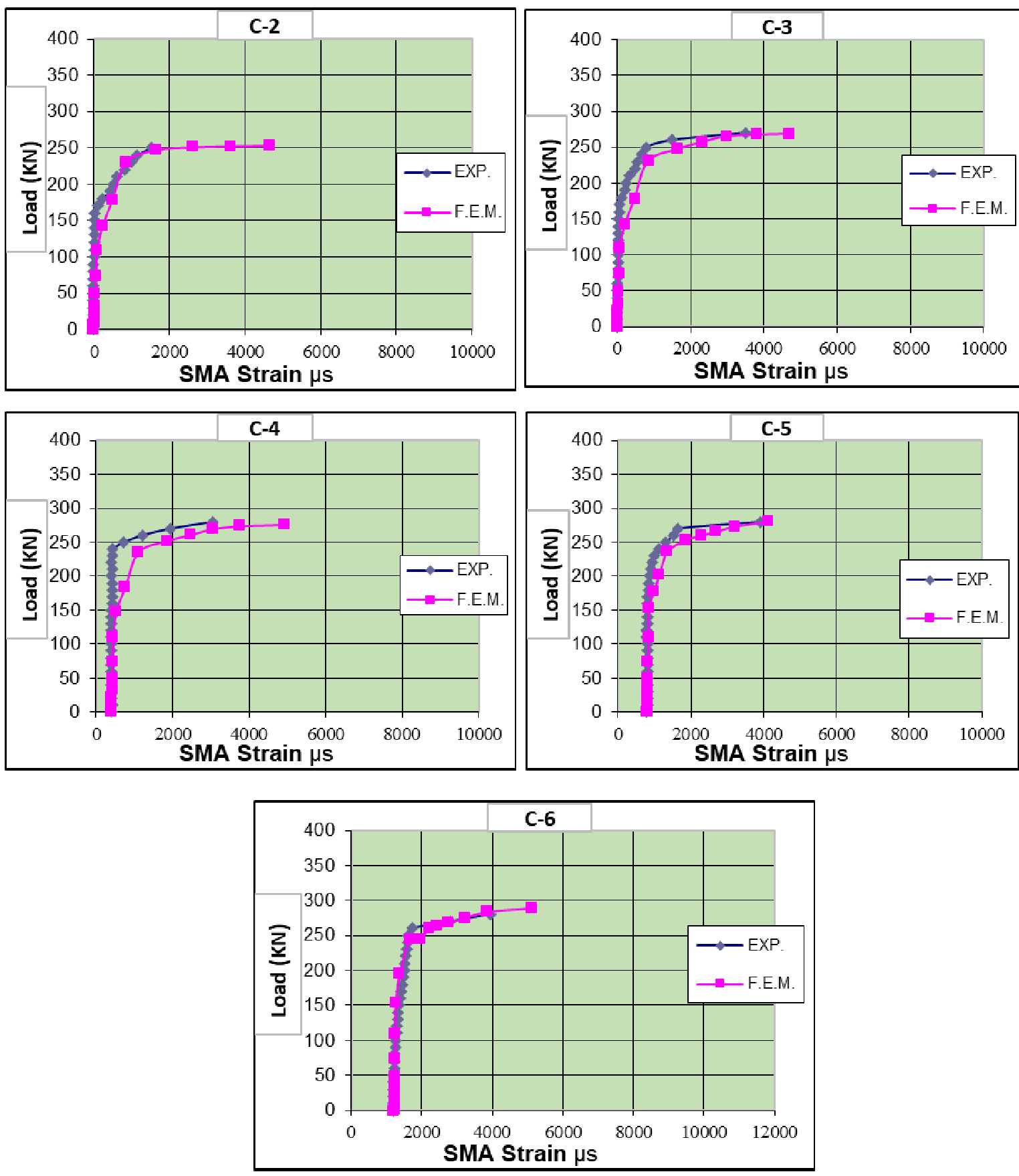

Fig. 12: Comparison between Experimental and Analytical SMA-Plates Strain for All Columns

\section{SUMMARY AND CONCLUSIONS}

The present study investigated the effect of active and passive confined concrete columns using a simple technique to apply active confinement with SMA-plates. The following summarizes the findings of this investigation:

1. SMA-plates were proven to be an efficient and simple way to actively confine concrete columns.

2. The increase of the column capacity started with $17 \%$ using passive confinement, and reached up to $38 \%$ for columns active ly confined with SMA-plates.

3. Increasing tension force in the external stirrups caused an increase of the capacity of columns confined with SMA.

4. Finite element models showed good agreement with the experimental results in the capacities and strain results. 
5. Finite element models also present a solid base for a future wide range study to verify the effect of active confinement using SMA-plates on different columns and obtain a methodology to calculate the capacity increase.

\section{REFERENCES}

1. Abdelrahman, K. and El-Hacha, R. (2015). Preliminary Experimental Investigation of Reinforced Concrete Columns Confined with NiTi SMA Wires. Proceedings of the 4th International Conference on Concrete Repair, Rehabilitation and Retrofitting (ICCRRR-4), Leipzig, Germany. 547-555.

2. American Concrete Institue. (2017). ACI Committee 440.2R-17: Guide for the Design and Construction of Externally Bonded FRP Systems for Strengthening Concrete Structures. Design Guidelines. 440.2R-34-440.2R-36.

3. Andrawes, B., Shin, M. and Wierschem, N. (2010). Active Confinement of Reinforced Concrete Bridge Columns Using Shape Memory Alloys. Journal of Bridge Engineering, 15(1), 81-89.

4. Atia, E. (2019). Confinement of Reinforced Concrete Columns Using Smart Material Alloys [Doctoral Dissertation, Al-Azhar University]. Cairo, Egypt, Al-Azhar.

5. Choi, E., Park, S., Cho, B. and Hui, D. (2013). Lateral reinforcement of welded SMA rings for reinforced concrete columns. Journal of Alloys and Compounds, 577(S), S756- S759.

6. Mander, J.B., Priestley, M.J.N., and Park, R., (1988). Theoretical Stress-Strain Model For Confined Concrete. Journal of Structural Engineering, 114(8), 1804-1826.

7. Park, J., Choi, E., Parkand, K. and Kim, H. (2011). Comparing the cyclic behavior of concrete cylinders confined by shape memory alloy wire or steel jackets. Smart Materials and Structures, 20 (1), 1-11.

8. Shin, M. and Andrawes, B. (2010). Experimental Investigation of Actively Confined Concrete Using Shape Memory Alloys. Engineering Structures, 32(2), 656-664.

9. Shin, M. (2012). Seismic Retrofit and Repair of Reinforced Concrete Bridge Columns Using Shape Memory Alloy Spirals. [Doctoral Dissertation, Department of Civil Engineering, Illinois University, Urbana, Champaign, USA. 